\title{
The Future is Here
}

President, American Academy of Sleep Medicine, Darien, IL; Professor and Chief, Division of Pulmonary Critical Care and Sleep Medicine, Department of Internal Medicine, Wayne State University School of Medicine, Detroit, MI

"If you can look into the seeds of time, and say which grain will grow and which will not, speak then unto me."

-William Shakespeare

$\mathrm{C}$ hange is the only constant in health care; and with change comes uncertainty, anticipation and trepidations. The adoption of the Patient Protection and Affordable Care Act, commonly known as the Affordable Care Act (ACA), is undoubtedly the most sweeping health care law passed by Congress since the creation of Medicare in 1965. The ACA is ushering in fundamental transformation that is likely to change the landscape of healthcare delivery in the U.S. It is very likely that the implementation of the ACA provisions will have significant unintended and unforeseen consequences for medical professionals, patients, insurers and businesses. ${ }^{1}$ Despite this uncertainty, it is clear that the ACA will shift the emphasis toward improving the outcome of care and reducing costs, perhaps by focusing on integration of care among providers and across care settings.

Within this broad context of change, the field of sleep medicine is undergoing its own radical transformation. Sleep medicine is no longer a specialty about a single disease, a single test, or a single device; instead, sleep medicine professionals provide care transcending organ based specialties, caring for one third of human life, a critical third that has direct impact on every aspect of health. The challenge before us is to develop care models that meet three aims: optimal patient experience, including quality and satisfaction; improving the health of population; and decreasing the cost of care.

What are the key themes that are likely to influence the practice of sleep medicine in the new era of health care reform? I will highlight several areas that require our attention in the coming year.

\section{Emergence of Out of Center Sleep Testing}

The diagnosis and management of obstructive sleep apnea (OSA) is associated with significant health care expenditure. Private payers have estimated that OSA-related claims expenses will increase anywhere from 20 to 40 percent annually. ${ }^{2}$ To decrease the direct cost of diagnostic services, many payers have adopted out of center sleep testing (OCST) for the evaluation of patients with suspected OSA. In fact, some private payers have begun to require utilization management review and preauthorization for diagnostic sleep testing as a cost containment measure. In some regions of the country these policies have caused OCST to become the predominant testing modal- ity for OSA, dramatically reducing the utilization of polysomnography (PSG). As a result, sleep specialists have been forced to evaluate our practice models, recognizing that we can no longer rely on laboratory PSG as our primary revenue stream. ${ }^{3}$ To ensure consistent high quality, the AASM has implemented a new accreditation program for OCST: more than 1,200 sleep medicine facilities have earned OCST accreditation from the AASM. In addition, the AASM has developed standards for evaluation of national suppliers who provide OCST services for sleep centers - the new approved OCST supplier designation. This arrangement allows the sleep specialist to focus on evaluating the patient, ordering the test, interpreting the results, making the diagnosis, and overseeing all follow-up care for the patient.

One of my immediate goals as president is to ensure that the AASM continues to advocate for our members on issues related to insurance coverage and reimbursement for sleep medicine services and to ensure that our patients receive high quality care. Our efforts to date have led to positive, open dialogue with payers and we will continue to address our members' concerns with these companies. Likewise, the AASM has been surveying members to gather data about preauthorization, denials and appeals. Our next step is to narrow our focus so that we can have the data necessary to identify inappropriate contracting practices by individual insurers in specific states, and developing "report cards" to show the impact of how insurer practices may be adversely affecting the care of patients with sleep disorders. We will need widespread participation from members in order to have the sample size necessary to generate meaningful data that will have an impact when we meet with insurers to discuss concerns, and I encourage you to participate in this vital survey.

\section{A New Business Model: Chronic Disease Management}

The new healthcare environment is shifting focus toward integrated care and long-term disease management of chronic sleep illness. The challenge before us is to develop models for coordinated care that promote high quality and cost effective care. This is a laudable goal that will favor accredited sleep centers and board certified sleep medicine physicians. The AASM leadership has been gathering thought leaders in the field to discuss the future of sleep medicine, to determine 
how the field of sleep medicine can enhance its relevancy by adopting the approach of the Patient Centered Medical Home $(\mathrm{PCMH})$, the use of clinical registries, and monitoring of health-related outcomes and tools. ${ }^{4}$ The AASM has been developing innovative new models for sleep specialists to provide comprehensive diagnostic and therapeutic services for patients with sleep disorders and co-morbid diseases. The Sleep Medicine Team model provides opportunities for synergistic partnership with primary care physicians (PCPs) who provide care to patients with suspected sleep disorders. Emerging evidence suggests that the involvement of PCPs in the evaluation and management of OSA may enhance patient access to sleep services. ${ }^{5,6}$ However, the Association of American Medical Colleges estimates that nearly one-third of all physicians will retire in the next decade, and 32 million younger Americans will become newly insured as a result of health care reform. Therefore, it is estimated that there will be 45,000 too few PCPs by $2020 .{ }^{7}$ Furthermore, PCPs are already overburdened with chronic disease management. An analysis of current practice guidelines for only 10 chronic illnesses found that they require more time than PCPs have available for patient care overall. ${ }^{8}$ Given these limitations, it would be unrealistic to expect PCPs to provide the comprehensive care that will be needed by the escalating population of patients with a sleep illness. Therefore, we envision that future comprehensive models of care will involve a synergistic partnership between the primary care physicians and sleep physicians within the framework of a comprehensive, accredited sleep center. Accordingly, patients with chronic sleep disorders will receive care by a multidisciplinary team of clinicians under the leadership of a sleep physician who will direct the care, ensure training and quality and interpret the diagnostic studies. The team could include clinical psychologists, nurse practitioners, physician assistants, or sleep technologists. The care team will interface seamlessly with the primary care physician to ensure delivery of timely, appropriate, high-quality and patient-centered care.

The evolution of a new paradigm of care will require thoughtful analysis to answer several key issues regarding the roles of team members, telehealth, and the development of quality metrics. A recent survey found that a large majority of patients indicated that they would be willing to see other clinicians such as a PA or NP for more timely care. ${ }^{9}$ Thus, it is important that we determine the training and education requirements and the potential roles of NPs/PAs in sleep-related patient care, as well as the roles of other members of the sleep team such as sleep psychologists and sleep technologists. The role of telehealth is another important aspect to consider when developing a new model of care for the sleep field. Sleep specialists already have integrated some telehealth techniques such as the use of "store and forward" technology to access and interpret the raw data from OCST studies. Furthermore, many sleep centers already are taking advantage of online telehealth programs and modem technology to monitor and track their patients' PAP adherence. However, sleep medicine has not widely embraced real-time telehealth techniques such as telemedicine visits, which allow patients to access specialized care remotely. Additionally, the sleep field has yet to specifically adopt a unified mechanism for remote patient monitor- ing of PAP adherence. Finally, the recently formed Quality Metrics Task Force will begin the vital task of defining successful outcomes for sleep medicine, which will help inform our planning. I am particularly excited about the forthcoming work of our expert task force, which comprises some of the most prominent thought leaders in our field.

The aforementioned issues will be discussed at a planned summit of key stakeholders to discuss the future model of care for sleep medicine. I intend for this meeting to produce actionable and practical steps forward that will address the most urgent and pressing needs of our members and the entire sleep field.

\section{Supply of Sleep Physicians}

The vitality of the sleep field requires increased awareness of sleep as a scientific discipline and a career path at all levels of medical education. We will develop novel ways to provide online resources to medical students in all stages of their career as elective education and to promote sleep as a specialty to future physicians. However, the supply may not match the demand. The growth in the number of AASM accredited sleep disorders centers is slowing, and board certification eligibility guidelines, which now require the completion of a sleep medicine fellowship, limit the number of candidates who can sit for the exam each year. Furthermore, it was noted recently that about 25 percent of the available 129 sleep medicine fellowship positions went unfilled in the most recent sleep medicine fellowship match. ${ }^{10}$ With data suggesting that the prevalence of OSA is increasing, ${ }^{11}$ there is the valid and immediate concern that the supply of sleep specialists will be unable to meet the demand for sleep medicine services in the near future. The AASM Board of Directors and the Sleep Medicine Curriculum Development Advisory Committee are discussing how to promote the sleep medicine subspecialty to make it more attractive to physicians in training. However, our model of care also must enable sleep medicine physicians to increase their patient base and expand their reach far beyond the walls of a sleep center.

\section{Leadership Development}

Urgent times such as these also demand that an organization such as the AASM have an involved and engaged membership, as well as strong and visionary leadership. We all have a stake in the future of our field, and we must work together to turn the challenges of today into opportunities for tomorrow. Therefore, one of my goals as president is to establish a leadership academy that will help identify and train the future leaders of the AASM. I want to ensure that there is a robust leadership pipeline that will supply the Board of Directors with an ample pool of leaders from which to draw for years to come.

\section{Conclusion}

The field of sleep medicine is facing great challenges and opportunities. However, I am confident in the AASM and in our membership, believing that we can overcome these challenges together. As sleep specialists, we are stewards of our patients' health. They need to sleep well, and they need our help. Their future health and well-being depends on the expertise that we offer them today. Change may be the law of life, but life is sustained by sleep. 


\section{CITATION}

Badr MS. The future is here. J Clin Sleep Med 2013;9(9):841-843.

\section{REFERENCES}

1. Pauly MV, Leive AA. The unanticipated consequences of postponing the employer mandate. N Engl J Med 2013 Jul 31. [Epub ahead of print].

2. CareCore National. Sleep management utilization \& quality management [Internet]. Cited 2013 Aug 2. Available at http://www.carecorenational.com/benefitsmanagement/sleep-management/sleep-management-utilization-and-qualitymanagement.aspx.

3. Quan SF; Epstein LJ. A warning shot across the bow: the changing face of sleep medicine. J Clin Sleep Med 2013:9:301-2.

4. Strollo PJ Jr, Badr MS, Coppola MP, Fleishman SA, Jacobowitz O, Kushida CA; American Academy of Sleep Medicine Task Force. The future of sleep medicine. Sleep 2011;34:1613-9.

5. Bendix J. Treating sleep disorders can wake up your bottom line [Internet]. Medical Economics 2013 July 25. Cited 2013 Aug 2. Available at http:/l medicaleconomics.modernmedicine.com/medical-economics/news/treatingsleep-disorders-can-wake-your-bottom-line.

6. Chai-Coetzer CL, Antic NA, Rowland LS, et al. Primary care vs specialist sleep center management of obstructive sleep apnea and daytime sleepiness and quality of life: a randomized trial. JAMA 2013;309:997-1004.

7. Association of American Medical Colleges. Fixing the doctor shortage [Internet]. Cited 2013 Aug 2. Available at https://www.aamc.org/advocacy/campaigns_ and_coalitions/fixdocshortage/.
8. Østbye T, Yarnall KS, Krause KM, et al. Is there time for management of patients with chronic diseases in primary care? Ann Fam Med 2005;3:209-14.

9. Dill MJ, Pankow S, Erikson C, Shipman S. Survey shows consumers open to a greater role for physician assistants and nurse practitioners. Health Aff (Millwood) 2013;32:1135-42.

10. Quan SF. Graduate medical education in sleep medicine: did the canary just die? J Clin Sleep Med 2013;9:101.

11. Peppard PE, Young T, Barnet JH, Palta M, Hagen EW, Hla KM. Increased prevalence of sleep-disordered breathing in adults. Am J Epidemiol 2013 Apr 14. [Epub ahead of print].

\section{SUBMISSION \& CORRESPONDENCE INFORMATION}

\section{Submitted for publication August, 2013}

Accepted for publication August, 2013

Address correspondence to: M Safwan Badr, M.D., F.A.A.S.M., Wayne State University, Detroit Medical Center; Pulmonary Critical Care, HUD, 3, 540 E. Canfield, Detroit, Ml 48201; Tel: (313) 745-2038; Fax: (313) 966-9833; E-mail: sbadr@dmc.org

\section{DISCLOSURE STATEMENT}

Dr. Badr is President of the American Academy of Sleep Medicine. 